\title{
A Multistage Fluidized Bed for the Deep Removal of Sour Gases: Proof of Concept and Tray Efficiencies
}

\author{
Rick T. Driessen, ${ }^{\circledR}$ Martin J. Bos, ${ }^{\circledR}$ and Derk W. F. Brilman*
}

Sustainable Process Technology, Faculty of Science and Technology, University of Twente, P.O. Box 217, 7500 AE Enschede, The Netherlands

\section{Supporting Information}

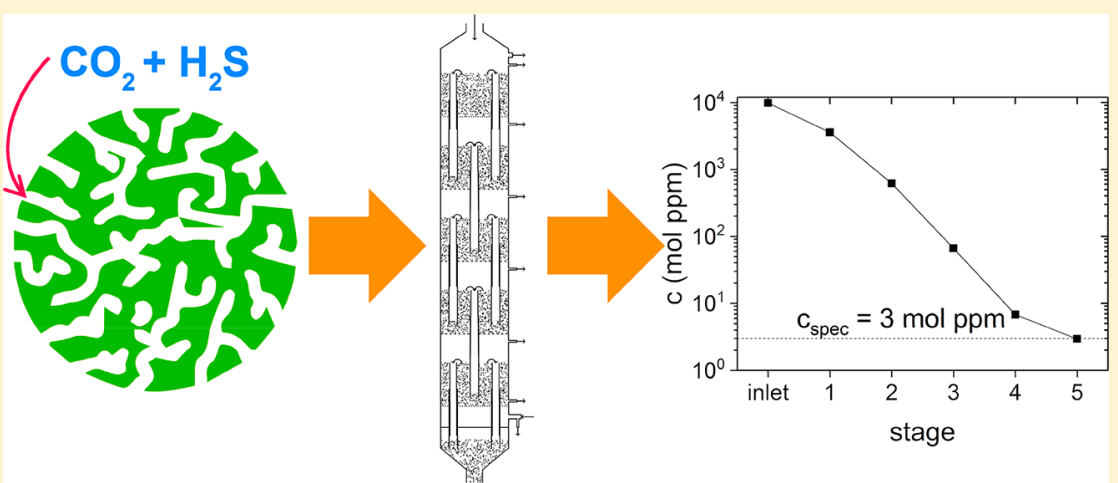

ABSTRACT: Currently there are significant amounts of natural gas that cannot be produced and treated to meet pipeline specifications, because that would not be economically viable. This work investigates a bench scale multistage fluidized bed (MSFB) with shallow beds for sour gas removal from natural gas using a commercially available supported amine sorbent. A MSFB is regarded as a promising adsorber type for deep sour gas removal to parts per million concentrations. A series of experiments was conducted using carbon dioxide as sour gas and nitrogen to mimic natural gas. Removal below 3 mol ppm was successfully demonstrated. This indicates that gas bypassing is minor (that is, good gas-solid contacting) and that apparent adsorption kinetics are fast for the amine sorbent applied. Tray efficiencies for a chemisorption/adsorption system were reported for one of the first times. Current experiments performed at atmospheric pressure strongly indicate that deep removal is possible at higher pressures in a multistage fluidized bed.

\section{INTRODUCTION}

Natural gas is one of the world's main energy sources. It is the third most important energy source after oil and coal. ${ }^{1}$ Many countries rely on the direct supply of natural gas. Besides its primary use as an energy source, natural gas is also an important hydrocarbon source for the chemical and petrochemical industries. ${ }^{2}$ Natural gas is considered to be the most clean and environmentally friendly fossil fuel because of its low carbon emissions. ${ }^{3}$

Currently, significant amounts of natural gas cannot be commercially extracted because of small gas field size, gas field location, or contamination. For example, according to a study of the Ministry of Economic Affairs of The Netherlands, about $170 \mathrm{~N} \mathrm{~m}^{3}$ in offshore gas fields in The Netherlands cannot be extracted at an acceptable cost, by adverse economy of scale due to small gas fields. ${ }^{4}$ Furthermore, $31-41 \%$ of the total amount of natural gas in the world cannot be extracted because of small gas fields or location (for example, deep offshore gas reserves or remote locations). ${ }^{5}$ Almost every gas field contains sour gas contaminants such as carbon dioxide $\left(\mathrm{CO}_{2}\right)$ and hydrogen sulfide $\left(\mathrm{H}_{2} \mathrm{~S}\right)$ which have to be removed. Golombok and Nikolic state that there are large individual gas fields in the world that are not in production because of high levels of sour gas contamination. ${ }^{6}$ These examples show that there are significant amounts of natural gas available worldwide that cannot be produced economically and may benefit from a novel, low cost sour gas removal technology.

The treatment of natural gas consists of many process steps. The removal of sour gases is especially capital and operationally intensive. With regard to $\mathrm{H}_{2} \mathrm{~S}$, Golombok and Nikolic estimate that $35 \%$ by volume of all natural gas reserves contains $\mathrm{H}_{2} \mathrm{~S}$ levels larger than $0.1 \mathrm{~mol} \%{ }^{6}$ The $\mathrm{H}_{2} \mathrm{~S}$ pipeline specification is only $3 \mathrm{ppm}$, and therefore, $99.7 \%$ from $\mathrm{H}_{2} \mathrm{~S}$ has to be removed. ${ }^{7}$ With respect to $\mathrm{CO}_{2}$, the typical $\mathrm{CO}_{2}$ concentration in natural gas is $0-30 \%$ where the $\mathrm{CO}_{2}$ pipeline specification is $1-3 \% .{ }^{7,8}$ For liquefied natural gas (LNG) applications, the $\mathrm{CO}_{2}$ specification is 50-150 ppm. ${ }^{9}$ Assuming a natural gas $\mathrm{CO}_{2}$ concentration of $\sim 10 \%$ and taking a $\mathrm{LNG} \mathrm{CO}_{2}$ specification of 100 ppm, $99.9 \%$ of the $\mathrm{CO}_{2}$ has to be removed. Considering

Received: November 25, 2017

Revised: February 27, 2018

Accepted: March 1, 2018

Published: March 1, 2018 
the high extents of removal for $\mathrm{H}_{2} \mathrm{~S}$ and $\mathrm{CO}_{2}$, it is conceivable that the removal of sour gas is capital and operationally intensive.

The benchmark process for the removal of sour gases from natural gas is the chemical absorption of sour gases into aqueous alkanolamine solutions, such as a methyldiethanolamine (MDEA) solution. ${ }^{10}$ This process has a high energy consumption related to the need to heat, cool, and partly evaporate an aqueous stream having a fairly high heat capacity. This research proposes the use of adsorption employing supported amine sorbents (SASs) as alternative to sour gas removal by aqueous alkanolamine solutions.

The use of adsorbents instead of absorbents can be energetically attractive because (a) adsorbents generally have a lower heat capacity than an aqueous stream and (b) the evaporation of water as a solvent is avoided because solid particles are used. Recently, some adsorbents for sour gas adsorption have been investigated. Most of these adsorbents are SASs; that is, they employ amine functional groups where sour gases can chemisorb. ${ }^{11-19}$ Chemisorption means a strong adsorbate-adsorbent interaction (compared to physisorption), which is needed for deep removal. Furthermore, by tuning the ratio of primary, secondary, and tertiary amine groups on the sorbent, the $\mathrm{H}_{2} \mathrm{~S} / \mathrm{CO}_{2}$ selectivity can be tuned, which supports the use for chemisorbents for the proposed application. ${ }^{19}$ In recent years, considerable experience was gained in using a commercial ion-exchange resin (Lewatit VP OC 1065) in $\mathrm{CO}_{2}$ adsorption for postcombustion $\mathrm{CO}_{2}$ capture. ${ }^{20,21}$ Sutanto et al. confirmed that this sorbent also adsorbs $\mathrm{H}_{2} \mathrm{~S}$ and, in addition, that it does not adsorb methane, which is the main constituent in natural gas, which is also proved by Sonnleitner et al. ${ }^{22,23}$ Since the sorbent (from now on called "amine sorbent") is available on a bulk scale, it was selected for this research to investigate the use of a bench scale MSFB for deep removal of sour gases.

Natural gas is available at elevated pressure, so it is probable that pressure swing adsorption (PSA) is used to desorb the sorbent in a future industrial application. For deep removal, the sorbent fed to the adsorber has to be very lean, and preliminary calculations show that a temperature swing adsorption (TSA) is advantageous to obtain a very lean sorbent. Therefore, this work applies a TSA. Just as an effective sorbent is important, so is the type of reactor. This work focuses on gas-solid processes where the sorbent circulates: this makes sure that every sorbent particle in the reactor is active. As an illustration, considering a fixed bed adsorption or desorption column, only the sorbent in the mass transfer zone is active because only this part of the sorbent is adsorbing or desorbing. The remainder of the sorbent is either at its equilibrium loading or does not see any adsorbates. In continuous gas-solid processes, this fraction of inactive sorbent can be minimized. The reactor has to fulfill the three requirements described below.

- High solids hold-up: The volume flow of natural gas in sour gas removal is high, which naturally means that future industrial plants will be large in scale. To prevent an excessive adsorber size, considering the large amount of acid gas to be removed and the potentially lower adsorption rates for deep removal, the overall solids hold-up has to be as high as possible, without creating zones with nonadsorbing (or saturated) particles.

- Counter-current contacting of gas and solids: The pipeline specification of $\mathrm{H}_{2} \mathrm{~S}$ is less than $3 \mathrm{~mol} \mathrm{ppm}$ while the concentration of $\mathrm{H}_{2} \mathrm{~S}$ in natural gas from the well can contain
0.1-15 mol \% of $\mathrm{H}_{2} \mathrm{~S}$. This means that the sorbent has to be very lean to obtain gas concentrations at the parts per million level. Therefore, counter-current contacting of gas and solids is required with a low degree of mixing.

- Good heat transfer: Heat effects in adsorption are significant: adsorption is preferred at low temperatures, whereas desorption is preferred at high temperatures according to the Van't Hoff equation. Furthermore, adsorption is exothermic, while desorption is endothermic. All of these heat effects stress that good heat management is important. Therefore, the heat transfer has to be high.

Keeping these three criteria in mind, a multistage fluidized bed (MSFB) is chosen as the adsorber type. In a MSFB, multiple fluidized beds are stacked on top of each other. Sour gas flows from bottom to top through gas distributors, and solid sorbent flows from top to bottom through downcomers. A MSFB satisfies all three criteria: (a) the typical solid hold-up of a fluidized bed is high (typically $0.5 \mathrm{~m}_{\mathrm{s}}^{3} / \mathrm{m}_{\text {bed }}{ }^{3}$ ); ${ }^{24}$ (b) due to staging, the degree of mixing of the solids is reduced and the gas and solid are contacted counter-currently; and (c) fluidized beds are known for their good heat transfer. ${ }^{24}$ With respect to a future industrial application, some aspects deserve more discussion.

Processes where solids have to be transported between different unit operations such as adsorption and desorption are known in chemical engineering; established technologies are circulating fluidized beds (CFB) and dual fluidized bed systems. A CFB employs cocurrent contacting of gas and solid and is not suitable for this application because counter-current contacting is required. A dual fluidized bed can be operated countercurrently, but the solid phase will be (partly) mixed because of vigorous mixing in a fluidized bed. This reduces ideal countercurrent contacting. In conclusion, established technologies such as CFBs and dual fluidized beds do not seem suitable to meet the requirements for this application. This motivates the use of a MSFB in this research.

Heat management is of major importance for the proposed application: the released exothermic heat of adsorption will be significant, whereas adsorption benefits from lower temperatures. In a future industrial application each stage in the adsorber and desorber will most likely be equipped with a heat exchanger to enable temperature control. The requirements for heat management will be system dependent and require a separate evaluation, outside the scope of the present work.

Currently, MSFBs are hardly used in industry; however, some examples do exist. MSFBs are used for adsorption processes such as (a) the removal of carbon disulfide $(\sim 0.1 \%)$ from air; (b) the removal of dichloromethane from contaminated gas; and (c) the removal of odor and solvents from air. All these examples use activated carbon as an adsorbent and focus on the trace removal (typically lower than $0.1 \%$ ) of adsorbates. ${ }^{24}$ Recently, MSFBs employing SASs have started to receive attention for $\mathrm{CO}_{2}$ capture. Krutka et al. developed a pilot-scale facility for postcombustion $\mathrm{CO}_{2}$ capture employing solid sorbents in a MSFB adsorber. ${ }^{25}$ More results on a pilot-scale facility for postcombustion $\mathrm{CO}_{2}$ capture using MSFBs are published by Nelson et al. in which they assess the techno-economic feasibility. ${ }^{26}$ The group of Meikap investigate MSFBs experimentally using various sorbents. ${ }^{27,28}$ Parallel and independent from our work at the University of Twente, the group of Hofbauer investigated a five-stage MSFB with supported amine sorbents with respect to fluid-dynamics and presented first experimental bench scale results. ${ }^{29-31}$ These 
researchers focus on the bulk removal (typically an inlet concentration of 5-10 mol \%) of adsorbates.

For the present case of $\mathrm{H}_{2} \mathrm{~S}$ sour gas removal, it is essential to investigate deep removal down to $3 \mathrm{ppm}$ of $\mathrm{H}_{2} \mathrm{~S}$ in a MSFB. This deep removal is not trivial because fluidized beds in the bubbling regime are known to show gas bypassing. Especially in the upper stages, low concentrations are present: any extent of gas bypassing complicates deep removal. In addition, the $\mathrm{H}_{2} \mathrm{~S}$ and $\mathrm{CO}_{2}$ concentrations in natural gas are at the percentage level, and thus bulk removal is relevant (next to deep removal down to parts per million levels of $\mathrm{H}_{2} \mathrm{~S}$ ). In this work, our first goal is to investigate if sour gas removal is possible from a percentage level ("bulk removal") down to parts per million level ("deep removal"). To our knowledge, this has not been investigated before within a MSFB system.

For conventional gas-liquid tray absorbers, a common design approach is the use of an equilibrium method combined with tray efficiencies. ${ }^{32}$ For all kinds of systems, equilibrium adsorption isotherms are presented in the literature, but tray efficiencies for adsorption are not known. To our knowledge, only Vanderschuren did report tray efficiencies for the adsorption of water on alumina, which is a combination of chemisorption, physisorption, and capillary condensation. ${ }^{33,34}$ As second goal, we investigate tray efficiencies for chemisorption by varying process parameters.

\section{MATERIALS AND METHODS}

2.1. Materials. This work uses Lewatit VP OC 1065 (the "amine sorbent") from Lanxess as an adsorbent. This amine sorbent is also known for its ability to adsorb sour gases. The backbone of this amine sorbent is polystyrene cross-linked with $8-10 \%$ of divinylbenzene. The polystyrene backbone is functionalized through benzylamine side groups. The primary amine group of benzylamine employs the function to adsorb $\mathrm{H}_{2} \mathrm{~S}$ and $\mathrm{CO}_{2}$. The main physical properties of the amine sorbent are given by Veneman et al. and Alesi and Kitchin. ${ }^{20,21}$

Veneman et al. reported that they did not see any sorbent capacity loss over $300 \mathrm{~h}$ of operation under desorption conditions of $90-120{ }^{\circ} \mathrm{C}$ in nitrogen $\left(\mathrm{N}_{2}\right)$. $^{21}$ Since this work uses the same sorbent and same desorption conditions, we can assume that the presented results are not influenced by possible sorbent degradation during the measurement series.

In all experiments, $\mathrm{N}_{2}$ (grade 4.7, purity $>99.997$ vol \%) and $\mathrm{CO}_{2}$ (grade 2.7, purity $>99.7$ vol \%) are used. Because neither methane nor $\mathrm{N}_{2}$ does adsorb onto this amine sorbent and only sour gases such as $\mathrm{CO}_{2}$ and $\mathrm{H}_{2} \mathrm{~S}$ adsorb, it is a valid assumption that $\mathrm{N}_{2}$ can mimic methane as seen in natural gas as bulk compound. ${ }^{22,23}$ In sour natural gas, both $\mathrm{CO}_{2}$ and $\mathrm{H}_{2} \mathrm{~S}$ may be present. To study the feasibility of deep removal of a sour compound, the sour gas $\mathrm{CO}_{2}$ (instead of $\mathrm{H}_{2} \mathrm{~S}$ ) is chosen. $\mathrm{H}_{2} \mathrm{~S}$ is toxic, flammable, and environmentally hazardous, so it would involve health, safety, and environment measures during experiments. Analogous to absorption in aqueous amines, we expect that $\mathrm{H}_{2} \mathrm{~S}$ will adsorb faster than $\mathrm{CO}_{2} \cdot{ }^{35}$ This means that any result obtained with $\mathrm{CO}_{2}$ will be on the conservative side.

2.2. Fixed Bed $\mathrm{CO}_{2}$ Sorbent Loading Measurements. The adsorption isotherm of $\mathrm{CO}_{2}$ on the amine sorbent in the range of $0-10000 \mathrm{~mol} \mathrm{ppm}$ and $301-336 \mathrm{~K}$ at atmospheric pressure was measured using adsorption saturation measurements in a fixed bed. The setup was equipped with a $16 \mathrm{~mm}$ inner diameter stainless steel tube, electrical heating on the wall to control the bed temperature, and two Brooks Instrument SLA5850 mass flow controllers for $\mathrm{N}_{2}$ and $\mathrm{CO}_{2}$ to set the inlet concentration. A LI-COR LI840A $\mathrm{CO}_{2}$ analyzer (0-20000 mol ppm) was used to measure the inlet concentration (via a bypass) and the outlet concentration.

Approximately $5 \mathrm{~g}$ of amine sorbent (previously dried in $\mathrm{N}_{2}$ ) was placed in the column. Before each adsorption experiment, the sorbent was desorbed in $\mathrm{N}_{2}$ at $90{ }^{\circ} \mathrm{C}$ until the outlet concentration was lower than $2 \mathrm{~mol} \mathrm{ppm}$ for $5 \mathrm{~min}$. Then, the sorbent was cooled down to the desired bed temperature. Once the bed temperature had been stable for $10 \mathrm{~min}$, the flow of $\mathrm{CO}_{2}$ was started, and then the saturation experiment started $(t$ $=0)$. The experiment was stopped once the outlet concentration $c_{\text {out }}$ had reached the inlet concentration for 30 min. Eventually, the sorbent loading $q$ could be calculated using the material balance of $\mathrm{CO}_{2}$ over the column, assuming that (a) the $\mathrm{CO}_{2}$ concentration $c$ is zero at the start of the experiment, (b) the sorbent loading is zero at the start of the experiment, and (c) the total $\mathrm{CO}_{2}$ molar flow rate $\Phi_{\text {mol }}$ is constant:

$$
\frac{c_{\text {out }} P}{R T} V_{\mathrm{g}}+q m_{\mathrm{s}}=\Phi_{\mathrm{mol}} t_{\mathrm{e}}-\Phi_{\mathrm{mol}} \int_{0}^{t_{\mathrm{e}}} c(t) \mathrm{d} t
$$

Please note that $c_{\text {out }}$ has the unit "mol ppm." The total hold-up of gas $V_{\mathrm{g}}$ above the sorbent and in pipelines is estimated with an empty column breakthrough experiment. Hence, the sorbent mass $m_{\mathrm{s}}$ is zero, and so the total hold-up $V_{\mathrm{g}}$ can be calculated using eq 1.

2.3. Bench Scale MSFB Setup. An illustration of the bench scale MSFB setup is shown in Figure 1. The main components of this setup are the five-stage adsorber column and the five-stage desorber column. $\mathrm{A} \mathrm{N}_{2} / \mathrm{CO}_{2}$ gas mixture is fed to the adsorber column ( $0.10 \mathrm{~m}$ inner diameter $)$ and rises upward to the gas outlet. The gas flow is regulated by two mass flow controllers: one for the $\mathrm{N}_{2}$ flow (Brooks Instrument SLA5851) and one for the $\mathrm{CO}_{2}$ flow (Brooks Instrument SLA5850). The amine sorbent flow is controlled with the bottom rotary valve (V3) by adjusting the motor voltage because the other rotary valves (V1 and V2) are turning faster than rotary valve $\mathrm{V} 3$. The sorbent particles are transported via a water-cooled riser $\left(8.5 \mathrm{~mm}\right.$ inner diameter, $10{ }^{\circ} \mathrm{C}$ wall temperature) at a superficial velocity of $4.4 \mathrm{~m} / \mathrm{s}$ to the top where a cyclone separates gas and solids. Eventually, the amine sorbent is fed to the adsorber column via a rotary valve. The amine sorbent falls downward through the adsorber column. Once the amine sorbent leaves the adsorber column, it is fed to the desorber column. The desorber column is a five-stage MSFB ( $0.10 \mathrm{~m}$ inner diameter) containing about $1.0 \mathrm{~kg}$ of dry amine sorbent. To desorb $\mathrm{CO}_{2}$ from the particles, each stage of the desorber column is equipped with heat tracing. During operation, the target desorption temperature is $100{ }^{\circ} \mathrm{C}$ and the superficial velocity is $0.11 \mathrm{~m} / \mathrm{s}$ for $\mathrm{N}_{2}$ as the stripping gas. Veneman et al. confirmed that the amine sorbent can be fully desorbed in $5 \mathrm{~min}$ in $\mathrm{N}_{2}$ at $100{ }^{\circ} \mathrm{C}^{21}$ The sorbent residence time in the desorber is $14 \mathrm{~min}$ for the highest solid flux. Therefore, we can assume that the amine sorbent is approaching full desorption $(q \approx 0 \mathrm{~mol} / \mathrm{kg})$ when re-entering the adsorber.

The internals of the adsorber column can be seen in more detail in Figure 2. Each stage is equipped with a stainless steel perforated plate (triangular pitch of round holes, $0.5 \mathrm{~mm}$ hole diameter, $1.5 \mathrm{~mm}$ pitch) and two standpipes (13 $\mathrm{mm}$ inner diameter). From stage to stage, the stages are rotated by $90^{\circ}$ as shown in Figure 3. The bottom stage has a metal sintered plate as a gas distributor to ensure a proper initial gas distribution. The standpipes allow the sorbent to fall down from stage to 


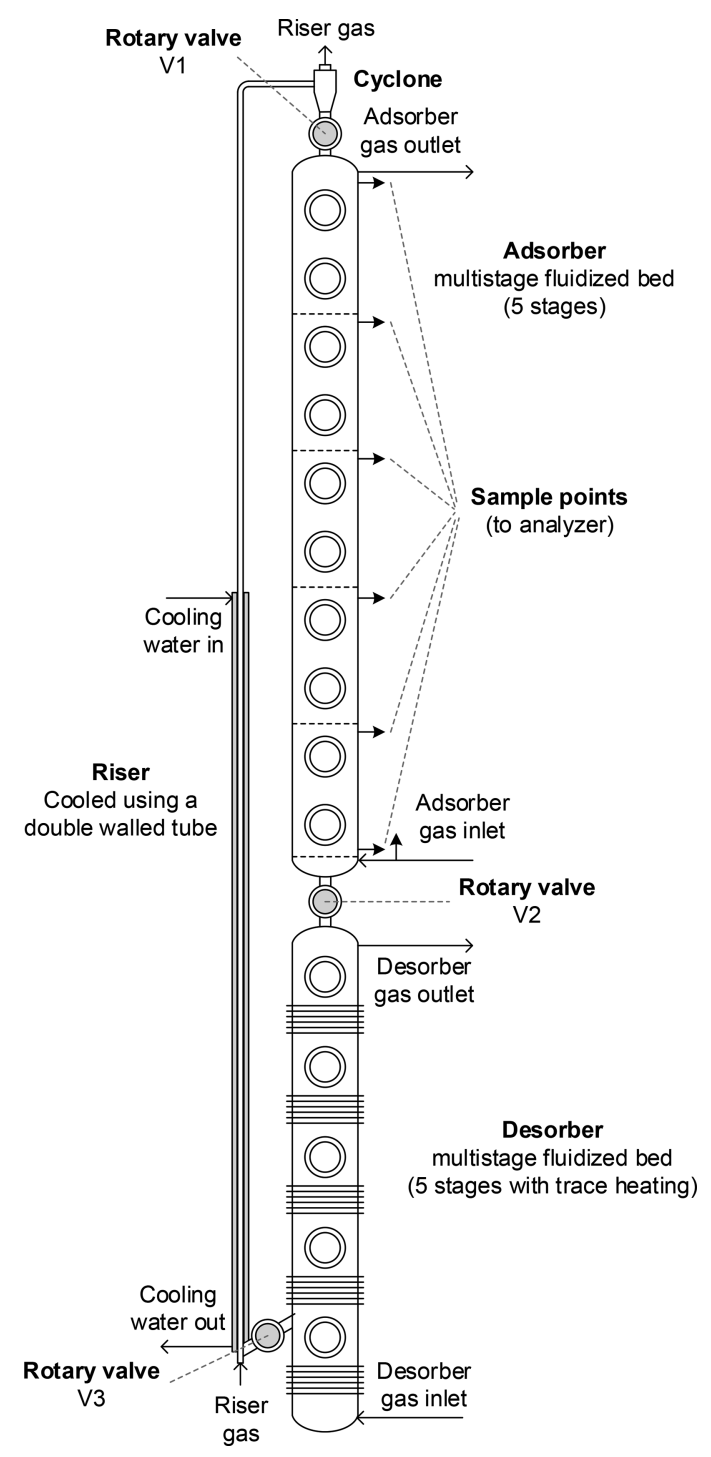

Figure 1. Schematic of the bench scale MSFB setup.

stage. The overflow height of the standpipe was set at $75 \mathrm{~mm}$. Please note that this yields a very shallow bed, especially when compared to conventional fluidized beds. The amine sorbent was mixed with graphite powder ( $0.3 \mathrm{wt} \%)$ to reduce electrostatic effects. There was about $1.1 \mathrm{~kg}$ of dry amine sorbent in the adsorber when all five stages with a pipe height of $75 \mathrm{~mm}$ were filled. Each stage is fitted with a thermocouple (K-type) $20 \mathrm{~mm}$ above the perforated plate to measure the bed temperature. Sample points in the freeboard measure the $\mathrm{CO}_{2}$ concentration (with a LI-COR LI-840A $\mathrm{CO}_{2}$ analyzer). Before measuring the $\mathrm{CO}_{2}$ concentration, $1.0-1.5 \mathrm{~h}$ was allowed for the system to reach a steady state.

During the experiments, the superficial velocity was varied between 0.18 and $0.41 \mathrm{~m} / \mathrm{s}$, the solid flux between 0.101 and $0.344 \mathrm{~kg} /\left(\mathrm{m}_{\mathrm{R}}^{2} \mathrm{~s}\right)$, and the inlet concentration of $\mathrm{CO}_{2}$ between 2500 and $10000 \mathrm{~mol} \mathrm{ppm}$.

\section{RESULTS}

3.1. Sorbent Characteristics. 3.1.1. $\mathrm{CO}_{2}$ Adsorption Isotherm. A sound adsorption isotherm is needed to be able to calculate tray efficiencies. Figure 4 shows the $\mathrm{CO}_{2}$ adsorption isotherm on the amine sorbent as measured with fixed bed

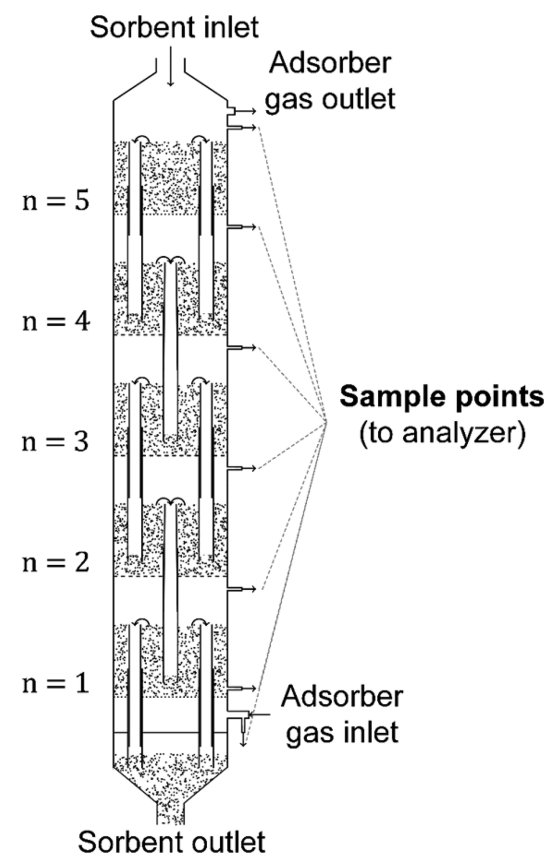

Figure 2. More detailed schematic of the adsorber MSFB internals. The stage number is denoted by $n$.

saturation experiments. The $\mathrm{CO}_{2}$ partial pressures range from 0 to $0.011 \mathrm{bar}$, and the temperature is varied from 301 to $336 \mathrm{~K}$. Section 3 of the Supporting Information discusses the reproducibility of these experiments. The Toth isotherm model (eq 5) is used to fit experimental data. ${ }^{36}$ A least-square method was used to obtain all Toth isotherm parameters which are shown in Table 1.

$$
\begin{aligned}
& q^{*}=\frac{n_{\mathrm{s}} b P_{\mathrm{CO}_{2}}}{\left(1+\left(b P_{\mathrm{CO}_{2}}\right)^{t}\right)^{1 / t}} \\
& b=b_{0} \exp \left(\frac{\Delta H}{R T_{0}}\left(\frac{T_{0}}{T}-1\right)\right) \\
& t=t_{0}+\alpha\left(1-\frac{T_{0}}{T}\right) \\
& n_{\mathrm{s}}=n_{\mathrm{s} 0} \exp \left(\chi\left(1-\frac{T}{T_{0}}\right)\right)
\end{aligned}
$$

3.1.2. Fluidization Properties. On the basis of the physical properties of the amine sorbent, it can be classified according to Geldart's classification for fluidization as Geldart B (sand-like) powder. ${ }^{24}$ For a Geldart B (sand-like) powder, bubbles will form as soon as the minimum fluidization velocity is reached, and small bubbles formed just above the gas distributor will grow while upflowing in the fluidized bed. These bubbles induce solid circulation and thereby mixing of the fluidized bed. Furthermore, when fluidizing the amine sorbent, fluidization will be in the bubbling regime for appropriate superficial gas velocities, which is common for Geldart B powders. ${ }^{24}$ This was visually confirmed by fluidizing the amine sorbent in a glass column (see section 1 of the Supporting Information). The minimum fluidization velocity of this amine sorbent was found to be $0.091 \mathrm{~m} / \mathrm{s}$ (see section 2 of the Supporting Information).

3.2. Tray Efficiency. The tray efficiency is a measure of the extent of reaching adsorption equilibrium. This work uses a 
(a)

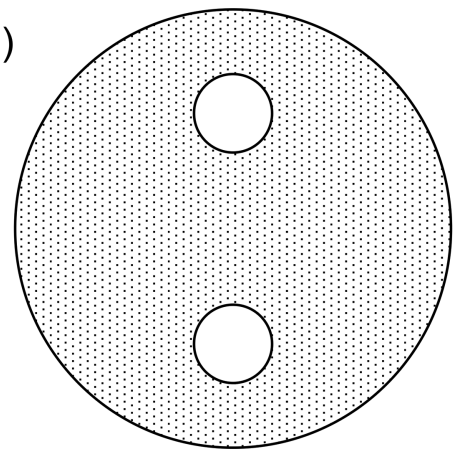

(b)

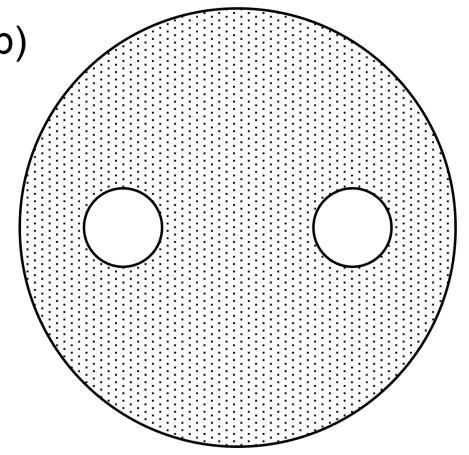

Figure 3. Top-view of the adsorber internals: (a) internals for stages 1, 3, and 5 and (b) internals for stages 2 and 4.

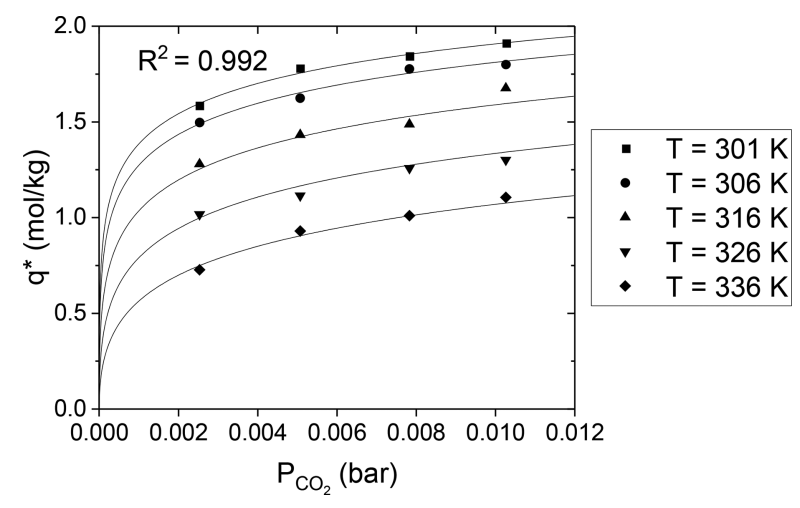

Figure 4. $\mathrm{CO}_{2}$ adsorption on Lewatit VP OC 1065 for $0-0.011$ bar at various temperatures. The individual data points represent fixed bed saturation experiments. The fitted curve is the Toth isotherm model.

Table 1. Toth Isotherm Parameters for the $\mathrm{CO}_{2}$ Adsorption Isotherm on Lewatit VP OC 1065 for $P_{\mathrm{CO}_{2}}=0-0.011$ bar and $T=301-336 \mathrm{~K}$

\begin{tabular}{ll}
\hline \multicolumn{1}{c}{ parameter } & \multicolumn{1}{c}{ value } \\
$t_{0}$ & 0.183 \\
$b_{0}(1 / \mathrm{bar})$ & $1.437 \times 10^{6}$ \\
$n_{\mathrm{s} 0}(\mathrm{~mol} / \mathrm{kg})$ & 3.954 \\
$\chi$ & 0 \\
$\alpha$ & 0.303 \\
$\Delta H(\mathrm{~J} / \mathrm{mol})$ & $1.433 \times 10^{5}$ \\
$T_{0}(\mathrm{~K})$ & 313.15 \\
\hline
\end{tabular}

definition analogous to the Murphree tray efficiency, which is defined by eq 2 :

$$
E_{\text {tray }, n}^{\mathrm{G}}=\frac{c_{n-1}-c_{n}}{c_{n-1}-c_{n}^{*}\left(q_{n}, T_{n}\right)}
$$

where $n$ is the stage number ( $n=1$ is the bottom tray, Figure 2) and $c_{n}{ }^{*}$ is the gas concentration in equilibrium with the sorbent loading $q_{n}$ and temperature $T_{n}$ at stage $n$ according to the adsorption isotherm. The sorbent loading $q_{n}$ is calculated via a mass balance over the column, assuming that the sorbent loading of the inflowing sorbent is zero as proved by Veneman et al. ${ }^{21}$ The definition assumes that each tray is ideally mixed, which means that the outlet gas concentration is assumed to be equal to the gas concentration at the tray.

In the gas-based Murphree tray efficiency (eq 2) $c_{n}{ }^{*}$ is in equilibrium with the sorbent leaving the tray; in the sorbentbased Murphree tray efficiency (eq 3 ), $q_{n}{ }^{*}$ is in equilibrium with the gas leaving the tray. This implies that the gas-based and sorbent-based Murphree tray efficiency are not equal because the gas and sorbent leaving the tray are not in equilibrium (if $E_{\text {tray }, n}^{\mathrm{G}} \neq 1$ ).

$$
E_{\mathrm{tray}, n}^{S}=\frac{q_{n+1}-q_{n}}{q_{n+1}-q_{n}^{*}\left(c_{n}, T_{n}\right)}
$$

The Hausen tray efficiency uses a modified version of the Murphree tray efficiency:

$$
E_{\text {tray }, n}^{\mathrm{H}}=\frac{c_{n-1}-c_{n}}{c_{n-1}-c_{n}^{*}\left(q_{n}^{\mathrm{e}}, T_{n}\right)}
$$

The main difference is the definition of $c_{n}{ }^{*}$ : in the Hausen tray efficiency, $c_{n}{ }^{*}$ is the gas concentration, which is in equilibrium with the sorbent in an infinitely long Concurrent gas-solid contactor. This also implies that the gas-based and sorbent-based Hausen tray efficiency are equal. Therefore, the Hausen tray efficiency could be considered a more satisfying definition for tray efficiency. However, the Murphree efficiency is by far the most used definition. ${ }^{37}$

3.3. Measurement Errors. In this study, only the steady state performance of the MSFB was investigated. Typically, it lasted $1.0-1.5 \mathrm{~h}$ to reach the steady state, which is on the same order of magnitude as the sorbent residence time in the adsorber and desorber. All reported concentrations and temperatures are time-averaged over a period of at least 120 s. The $95 \%$ confidence interval in concentration was calculated, and it was found that it was always lower than $1 \%$ of the measured concentration. Therefore, no error bars are shown in any figure. For the temperature measurement, K-type thermocouples are used, so a measurement error of $\pm 1.5{ }^{\circ} \mathrm{C}$ can be expected, reflecting thermocouple standards.

Heat effects in the MSFB and their consequences on concentration are significant. Considering the energy balance on the MSFB, four terms have to be taken into account: (a) hot solids from the desorber are fed to the top of the adsorber; (b) cold gas $\left(T \sim 20^{\circ} \mathrm{C}\right)$ is fed to the bottom of the adsorber; (c) the adsorption process is exothermic; and (d) there is a heat loss to the environment. The latter is a strong function of the ambient temperature: a duplicate experiment at two different ambient temperatures $\left(T=24^{\circ} \mathrm{C}\right.$ and $\left.T=27^{\circ} \mathrm{C}\right)$ resulted in significant differences in the outlet concentrations $\left(c_{\text {out }}=230\right.$ mol ppm and $c_{\text {out }}=710 \mathrm{~mol}$ ppm, respectively) at otherwise identical feed composition and process conditions (see section 5 of the Supporting Information). This exemplifies the large sensitivity of temperature to concentration, and consequently, this complicates the verification of experimental reproducibility. However, this is unavoidable in the present MSFB configuration, and therefore all stage temperatures are shown in 
section 4 of the Supporting Information. More details on duplicate experiments can also be found in section 5 of the Supporting Information.

When calculating the tray efficiencies, the assumption is made that the sorbent fed to the adsorber is approaching full desorption $(q \approx 0 \mathrm{~mol} / \mathrm{kg})$, which may not be entirely true. The validation of this assumption deserves some discussion. For trays with a high sorbent loading (that is, the lowermost stages), the effect of a not fully desorbed sorbent on the tray efficiency is nil. The contribution of the inflowing sorbent loading to the actual sorbent loading and so the tray efficiency at a certain tray will be minor, if not negligible. With respect to stages with a lower sorbent loading (that is, the uppermost stages), the effect of a possible not fully desorbed sorbent would be most pronounced, and the situation becomes more complex. It can be shown that (a) for lower sorbent loadings the maximum error in the gas-based Murphree tray efficiency induced is 0.05 units and (b) all reported tray efficiencies are on the conservative side. This is explained in section 6 of the Supporting Information.

3.4. Proof of Concept, Concentration Profiles, and Tray Efficiencies. The effect of superficial velocity on the outlet concentration is shown in Figure 5. The inlet concentration was set at $10000 \mathrm{~mol} \mathrm{ppm}$. The removal efficiencies are high: $94.2 \%$ for a superficial velocity of $0.41 \mathrm{~m} / \mathrm{s}$ and $99.9 \%$ for a superficial velocity of $0.18 \mathrm{~m} / \mathrm{s}$, whereas the gas residence time is only increasing from 0.9 to $2.1 \mathrm{~s}$. This leads to

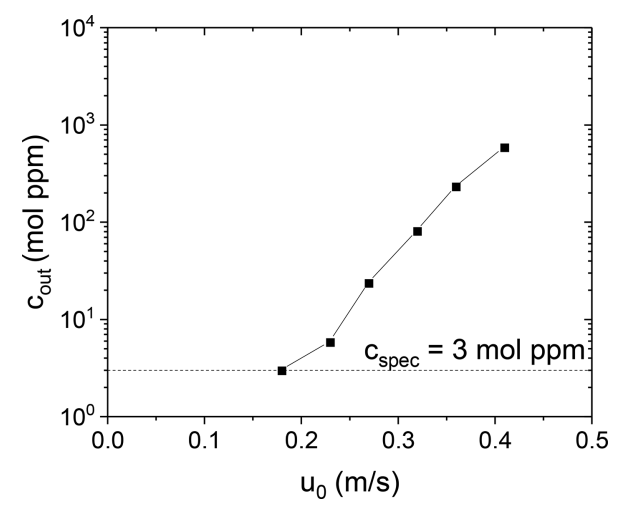

Figure 5. Outlet concentration as a function of the superficial velocity in the five stage MSFB. The dashed line indicates the $\mathrm{H}_{2} \mathrm{~S}$ pipeline specification $\left(c_{\mathrm{in}}=10000 \mathrm{ppm}, S=0.101 \mathrm{~kg} /\left(\mathrm{m}_{\mathrm{R}}{ }^{2} \mathrm{~s}\right)\right.$, pipe height $=75$ $\mathrm{mm})$. the hypotheses that (a) gas bypassing is small (that is, good gas-solid contacting), especially considering that shallow beds are used, and (b) that apparent adsorption kinetics (that is, intrinsic adsorption kinetics in combination with external mass transfer and intraparticle mass transfer) are fast, in line with findings by Schöny et al. ${ }^{30}$ However, additional modeling is needed to confirm both hypotheses by including quantifiable effects such as gas-solid contacting, hold-ups, intraparticle mass transfer, and intrinsic adsorption kinetics.

The lowest concentration measured $(3.0 \mathrm{~mol} \mathrm{ppm})$ is probably at the detection limit of the $\mathrm{CO}_{2}$ analyzer. This was checked by measuring a calibrated gas mixture of $2.9 \pm 0.1 \mathrm{~mol}$ ppm of $\mathrm{CO}_{2}$ in $\mathrm{N}_{2}$, where the $\mathrm{CO}_{2}$ analyzer indicated a concentration of $3.9 \mathrm{~mol} \mathrm{ppm}$. The difference between the measured and the calibrated concentration is only $1 \mathrm{~mol} \mathrm{ppm}$, equivalent to $0.01 \%$ of the $\mathrm{CO}_{2}$ analyzer full scale range stressing the detection limit of the $\mathrm{CO}_{2}$ analyzer. Since in this range, the actual concentration is lower than the measured concentration; it can be concluded that deep removal below 3 mol ppm as required for $\mathrm{H}_{2} \mathrm{~S}$ removal in a MSFB is possible, especially when realizing that $\mathrm{CO}_{2}$ will adsorb slower than $\mathrm{H}_{2} \mathrm{~S}$.

The column profiles for gas concentration and tray efficiency are shown in Figure 6. The temperature profiles are shown in section 4 of the Supporting Information. Decreased superficial velocities result in lower gas concentrations and higher tray efficiencies. By decreasing the superficial velocity, the gas residence time increases, so more time is available to adsorb $\mathrm{CO}_{2}$ and to reach equilibrium. An additional interpretation is that the adsorption of $\mathrm{CO}_{2}$ is reaction rate limited. Furthermore, Vanderschuren also reported data for tray efficiencies at various superficial velocities for the adsorption of water on alumina. ${ }^{33}$ In that study, a certain optimum superficial velocity was observed when the tray efficiency reaches a maximum value (for a fixed bed height of $0.05 \mathrm{~m}$ ). Vanderschuren interprets his results with the Cholette and Cloutier model. ${ }^{38}$ This model assumes that (a) the solids fraction $x_{\mathrm{s}}$ bypasses the bed, (b) a bed fraction $y_{\text {bed }}$ is ideally mixed, and (c) a bed fraction $1-y_{\text {bed }}$ is in a "dead zone." With increasing superficial velocity, the amount of solids bypassing increases due to more vigorous bubbling behavior, whereas the dead volume $1-y_{\text {bed }}$ decreases due to better mixing. This can explain the optimum observed by Vanderschuren. ${ }^{33}$ However, we do not see that optimum in Figure 6. When this theory is applied to the data presented here, a conclusion can be drawn that solids bypassing is minor. Besides, when increasing the superficial velocity, bubbles might grow, which will contribute (a)

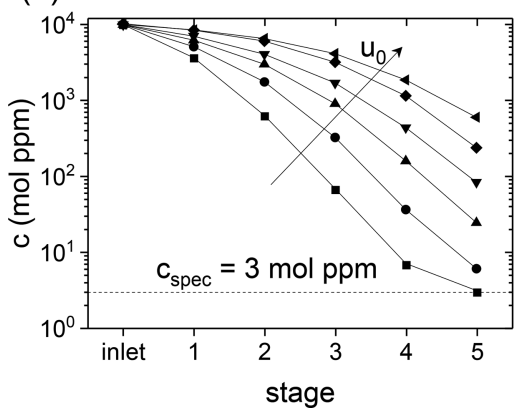

(b)

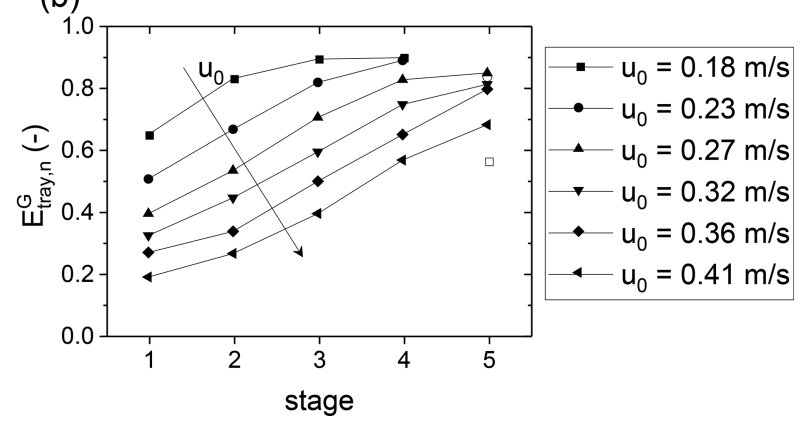

Figure 6. Column profiles for varying superficial velocities: (a) concentration and (b) tray efficiency. Both figures share the same legend ( $c_{\text {in }}=10000$ mol ppm, $S=0.101 \mathrm{~kg} /\left(\mathrm{m}_{\mathrm{R}}^{2} \mathrm{~s}\right)$, pipe height $\left.=75 \mathrm{~mm}\right)$. The open markers indicate that the calculated tray efficiency is too low, because the corresponding concentrations are at the detection limit of the $\mathrm{CO}_{2}$ analyzer. 
(a)

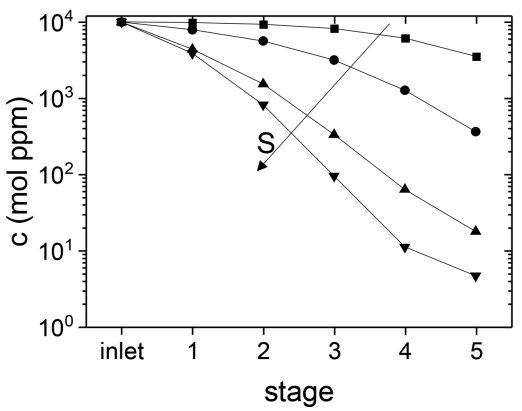

(b)

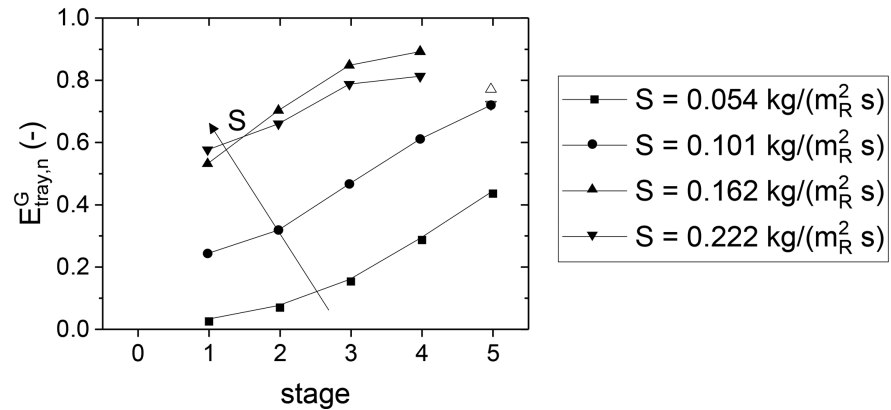

Figure 7. Column profiles for varying solid fluxes: (a) concentration and (b) tray efficiency. Both figures share the same legend $\left(c_{\text {in }}=10000\right.$ mol $\mathrm{ppm}, u_{0}=0.32 \mathrm{~m} / \mathrm{s}$, pipe height $=75 \mathrm{~mm}$ ). The open markers indicate that the calculated tray efficiency is too low, because the corresponding concentrations are at the detection limit of the $\mathrm{CO}_{2}$ analyzer.

(a)

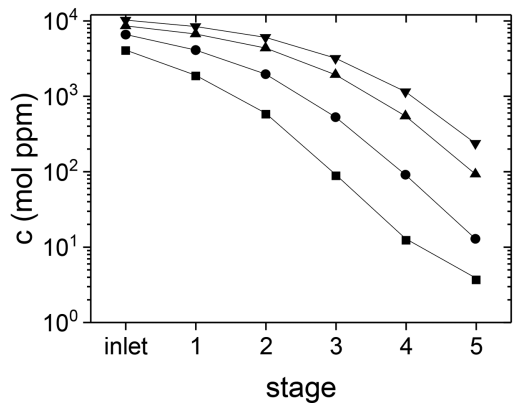

(b)

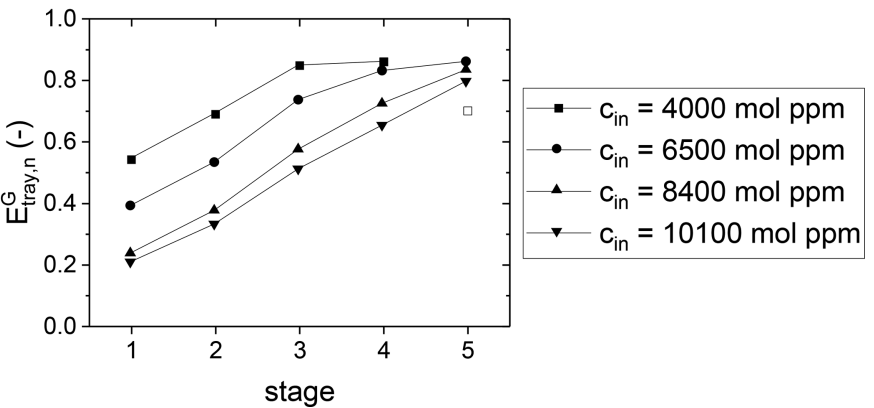

Figure 8. Column profiles for varying inlet concentrations: (a) concentration and (b) tray efficiency. Both figures share the same legend $\left(u_{0}=0.32\right.$ $\mathrm{m} / \mathrm{s}, S=0.101 \mathrm{~kg} /\left(\mathrm{m}_{\mathrm{R}}^{2} \mathrm{~s}\right)$, pipe height $\left.=75 \mathrm{~mm}\right)$. The open markers indicate that the calculated tray efficiency is too low, because the corresponding concentrations are at the detection limit of the $\mathrm{CO}_{2}$ analyzer.

(a)

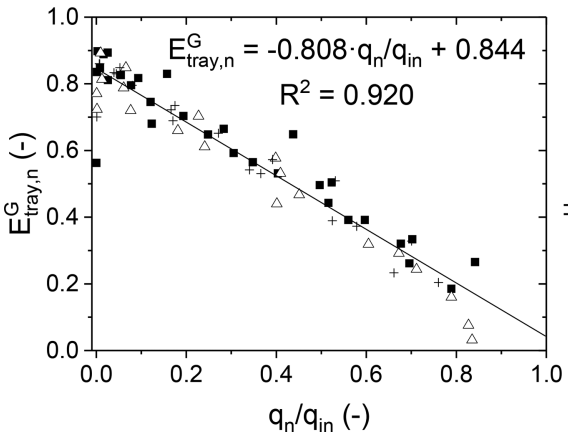

(b)

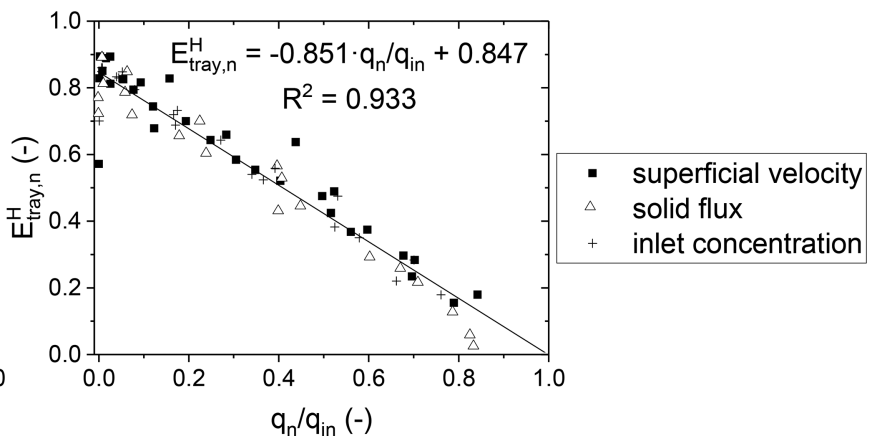

Figure 9. Correlation between the tray efficiency and relative sorbent loading: (a) Murphree tray efficiency and (b) Hausen tray efficiency. The data points are taken from all MSFB experiments for varying superficial velocity, solid flux, and inlet concentration (Figures 6-8) as indicated by the legend.

to some extent of gas bypassing. However, because the uptake of $\mathrm{CO}_{2}$ is very fast, we suspect that gas bypassing as a whole is of little importance. Quantification of this phenomenon is not yet possible and will be part of a further study.

The dependency on the solid flux is shown in Figure 7. A higher solid flux results in lower gas concentrations and higher tray efficiencies. When the solid flux is increased, the sorbent loading will be lower, because for the same amount of gas (that is, the same superficial velocity) more sorbent is available to adsorb $\mathrm{CO}_{2}$. This increases the number of free adsorption sites. This results in lower gas concentrations and higher tray efficiencies. This is in line with experimental data from Vanderschuren who also reported higher tray efficiencies for higher solid fluxes. ${ }^{33}$ One remarkable observation is that the tray efficiencies at $S=0.162 \mathrm{~kg} /\left(\mathrm{m}_{\mathrm{R}}{ }^{2} \mathrm{~s}\right)$ are higher than those at $S=0.222 \mathrm{~kg} /\left(\mathrm{m}_{\mathrm{R}}^{2} \mathrm{~s}\right)$. This is most likely caused by a significant difference in the ambient temperature (see section 4 of the Supporting Information for temperature profiles).

Looking at the tray efficiencies (Figure $7 b$ ), there exists a clear distinction between the various solid fluxes. When considering the concentrations and tray efficiencies at $S=$ $0.054 \mathrm{~kg} /\left(\mathrm{m}_{\mathrm{R}}{ }^{2} \mathrm{~s}\right)$, it seems that the sorbent is almost saturated with adsorbed $\mathrm{CO}_{2}$. This slows the adsorption kinetics: in line with linear driving force models, the adsorption kinetics are proportional to the number of free adsorption sites: $q^{*}\left(c_{n}\right)-$ $q_{n}$. The removal efficiency is mainly limited by equilibrium: in 
the lower stages (for example, stages 1 and 2), almost no $\mathrm{CO}_{2}$ is adsorbed anymore, for example.

The dependency of inlet concentration is shown in Figure 8: lower inlet concentrations result in lower concentrations at each stage. A remarkable observation is that lower inlet concentrations lead to higher tray efficiencies, which may be counterintuitive because higher gas concentrations should increase the reaction rate. Why this is not the case is explained further in the next section.

3.5. Correlating Tray Efficiencies. From all the tray efficiency profiles (Figures 6,7, and 8), it can be seen that the tray efficiency roughly increases with stage number. Vanderschuren reported a similar trend for a combination of physisorption, chemisorption, and capillary condensation. ${ }^{33,34}$ The observed trend can be linked to the sorbent loading, which is decreasing with stage number (because lean sorbent is fed from the top and becomes saturated while moving downward). The hypothesis is that high relative sorbent loadings correlate strongly with low tray efficiencies.

Figure 9 shows the correlation between the tray efficiency (both Murphree and Hausen, eq 2 and eq 3, respectively) and the relative sorbent loading $q_{n} / q_{\text {in }}$. The sorbent loading at inlet conditions $q_{\text {in }}$ is defined as the adsorption isotherm sorbent loading in equilibrium with the inlet concentration and the temperature at stage 1 . Both the Murphree and Hausen tray efficiency decrease with increasing relative sorbent loading. It is suggested here that the low tray efficiencies at the trays with high sorbent loadings are related to the low adsorption kinetics on that tray. This is in accordance with linear driving force models which state that adsorption kinetics are closely proportional to the number of free adsorption sites $q^{*}\left(c_{n}\right)-$ $q_{\mathrm{n}}{ }^{39}$

A linear equation was fitted on both data sets, and both linear relations were found to be statistically significant with $95 \%$ confidence using the student's $t$ test. Looking at the coefficient of determination $R^{2}$ in Figure 9, the Hausen tray efficiency correlates slightly better than the Murphree tray efficiency. Please note that the obtained relations are only valid for the amine sorbent, overflow height $(75 \mathrm{~mm})$, gas distributor, and diameter applied. With respect to the latter, if the overflow height is increased, the gas and solid residence times increase, allowing more time to attain equilibrium and hence tray efficiencies will increase. Therefore, one could obtain a linear relation for every overflow height. To include effects such as overflow height and to improve tray efficiency predictions, identification and quantification of transport phenomenasuch as gas-solid contacting, hold-ups, hydrodynamics, intraparticle mass transfer, and intrinsic adsorption kinetics-have to be investigated in more detail.

One might postulate that also the gas concentration would also affect adsorption kinetics and hence tray efficiencies, because adsorption kinetics are more or less proportional to the gas concentration at constant sorbent loading. ${ }^{40}$ However, it was found (Figure $8 \mathrm{~b}$ ) that lower inlet concentrations lead to higher tray efficiencies, which disproves such a postulation. In all the experiments conducted, the amount of gas supplied was always higher than the amount of solids supplied on a mass basis. The gas-to-solid ratio $F_{\mathrm{G}} / F_{\mathrm{S}}$ did range from 1.7 to 4.7 $\mathrm{kg}_{\mathrm{G}} / \mathrm{kg}_{\mathrm{s}}$. This means that for every mole of $\mathrm{CO}_{2}$ adsorbed, the change in sorbent loading (and hence the number of free adsorption sites) is higher than the change in gas concentration. This might explain that the effect of the number of free adsorption sites on the tray efficiency is more dominant than the effect of gas concentration.

\section{DISCUSSION}

This paper concludes that the effect of gas bypassing on the removal efficiency in a MSFB targeting deep removal of sour gases by chemisorption is minor. However, this was measured in a fairly small diameter column (inner diameter $0.10 \mathrm{~m}$ ). The amount of gas bypassing in a bubbling fluidized bed is dependent on scale: higher and wider beds result in an increase of gas bypassing by growing bubbles. Therefore, it is not trivial that the amount of gas bypassing will be the same when scaling up. However, if one decides to keep the bed shallow $(75 \mathrm{~mm}$ bed height in this work), then there is a high probability of operating with low gas bypassing. ${ }^{24}$

Only experiments at atmospheric pressure have been performed in this work. These results are valid for postcombustion carbon capture, but not necessarily for sour gas removal from natural gas where the adsorber has to operate at elevated pressures. One can nevertheless reason that it is also possible to obtain deep removal $(<3 \mathrm{ppm})$ at elevated pressures. When increasing the total pressure, the $\mathrm{H}_{2} \mathrm{~S}$ and $\mathrm{CO}_{2}$ partial pressures will also increase at a fixed volume fraction and hence the adsorber will operate in the higher partial pressure regime of the adsorption isotherm. This means that the required sorbent loading for $<3 \mathrm{ppm}$ of $\mathrm{H}_{2} \mathrm{~S}$ is higher and hence regeneration is less stringent. In conclusion, achieving deep removal will be possible also at elevated pressures.

However, the question how tray efficiencies are affected by elevated pressure in terms of uptake rate, mass transfer, and hydrodynamics needs further study. From the literature, some observations are known when pressure increases. First, a fluidized bed becomes more homogeneous. Second, the local Sherwood number increases. Third, the intrinsic adsorption kinetics speed up because of increasing concentrations. All in all, most likely an increasing pressure will enhance the apparent uptake rate and, so, tray efficiency, but it has to be confirmed. ${ }^{41}$

\section{CONCLUSIONS}

In this research, a MSFB contactor was used to study bulk and deep removal of $\mathrm{CO}_{2}$ by chemisorption in view of sour gas $\left(\mathrm{H}_{2} \mathrm{~S}\right.$ and $\left.\mathrm{CO}_{2}\right)$ removal from natural gas streams and for postcombustion carbon capture employing SASs. In a countercurrent five-stage MSFB using shallow beds, very high removal efficiencies (up to 99.9\%) were obtained indicating that gas bypassing is minor (and so gas-solid contacting is good) and that apparent adsorption kinetics are fast for the amine sorbent applied. It was demonstrated that the required deep removal down less than a $3 \mathrm{~mol}$ ppm level can be achieved. Furthermore, the effects of superficial velocity, solid flux, and inlet concentration on tray efficiency have been reported for one of the first times for a MSFB in combination with a chemisorption process. It was found that the sorbent loading has a significant effect on the tray efficiency: higher sorbent loadings decrease the tray efficiency. More work is however required to identify and quantify the underlying phenomena for the correlation found. To conclude, a MSFB is a promising reactor type for adsorptive removal of sour gases from natural gas. 


\section{ASSOCIATED CONTENT}

\section{S Supporting Information}

The Supporting Information is available free of charge on the ACS Publications website at DOI: 10.1021/acs.iecr.7b04891.

Fluidization regime of the amine sorbent, minimum fluidization velocity, reproducibility of fixed bed experiments, full column profiles (concentration, temperature, and tray efficiency), and duplo experiments in the multistage fluidized bed (PDF)

\section{AUTHOR INFORMATION}

\section{Corresponding Author}

*E-mail: d.w.f.brilman@utwente.nl.

ORCID $\odot$

Rick T. Driessen: 0000-0003-0214-6823

Martin J. Bos: 0000-0002-8049-8261

Notes

The authors declare no competing financial interest.

\section{ACKNOWLEDGMENTS}

This research was carried out in the context of the Compact Advanced Sour gas Processing (CASPer) project, coordinated by the Institute for Sustainable Process Technology and cofinanced by the Ministry of Economic Affairs of The Netherlands (RVO.nl project number, TEEI115008). Benno Knaken, Johan F.H. Agterhorst, and Karst van Bree (Sustainable Process Technology group, University of Twente) are acknowledged for their craftsmanship during the construction of the bench scale MSFB. The authors thank Peter Hauwert (Frames Oil \& Gas Processing), Jurriaan Boon, JeanPierre A.Z. Pieterse (Energy Research Centre of The Netherlands), and Ries A.H. Janssen (Shell Global Solutions International $\mathrm{BV}$ ) for fruitful discussions during project meetings. Robin Vet is acknowledged for providing sorbent fluidization snapshots.

\section{NOMENCLATURE}

$c=$ mole fraction, $\mathrm{mol}_{\mathrm{CO}_{2}} / \mathrm{mol}_{\mathrm{G}}$

$E_{\text {tray }}^{\mathrm{G}}=$ gas-based Murphree tray efficiency

$E_{\text {tray }}^{\mathrm{H}}=$ Hausen tray efficiency

$E_{\text {tray }}^{S}=$ sorbent-based Murphree tray efficiency

$F=$ mass flow, $\mathrm{kg} / \mathrm{s}$

$g=$ gravitational acceleration, $\mathrm{m} / \mathrm{s}^{2}$

$L=$ bed height, $\mathrm{m}$

$m_{\mathrm{s}}=$ sorbent mass, $\mathrm{kg}_{\mathrm{s}}$

$P=$ pressure, $\mathrm{Pa}$

$q=$ sorbent loading, $\mathrm{mol}_{\mathrm{CO}_{2}} / \mathrm{kg}_{\mathrm{s}}$

$R$ = ideal gas constant, $\mathrm{J} /(\mathrm{mol} \mathrm{K})$

$S=$ sorbent flux, $\mathrm{kg}_{\mathrm{s}} /\left(\mathrm{m}_{\mathrm{R}}^{2} \mathrm{~s}\right)$

$T=$ temperature, $\mathrm{K}$

$t_{\mathrm{e}}=$ time needed to reach equilibrium, $\mathrm{s}$

$u=$ superficial velocity, $\mathrm{m}_{\mathrm{G}}^{3} /\left(\mathrm{m}_{\mathrm{R}}^{2} \mathrm{~s}\right)$

$V_{\mathrm{g}}=$ fixed bed gas hold-up, $\mathrm{m}_{\mathrm{G}}{ }^{3}$

$x_{\mathrm{s}}=$ bypassed solid fraction, $\mathrm{kg}_{\text {bypass }} / \mathrm{kg}_{\mathrm{s}}$

$y_{\text {bed }}=$ bed fraction, $\mathrm{m}_{\text {bed }}{ }^{3} / \mathrm{m}_{\mathrm{R}}{ }^{3}$

\section{Greek Symbols}

$\varepsilon=$ porosity, $\mathrm{m}_{\mathrm{G}}{ }^{3} / \mathrm{m}_{\mathrm{R}}{ }^{3}$

$\Phi_{\text {mol }}=$ molar flow rate, $\mathrm{mol}_{\mathrm{CO}_{2}} / \mathrm{s}$

$\rho=$ density, $\mathrm{kg} / \mathrm{m}^{3}$

\section{Subscripts/Superscripts}

$\mathrm{e}=$ in equilibrium with gas outlet and sorbent outlet

$\mathrm{G}=$ gas

in $=$ inlet

$\mathrm{mf}=$ minimum fluidization

$\mathrm{n}=$ stage number

out $=$ outlet

$\mathrm{R}=$ reactor

$\mathrm{s}=$ sorbent

$0=$ superficial

* = in equilibrium with the adsorption isotherm

\section{REFERENCES}

(1) Key World Energy Statistics; International Energy Agency, 2016.

(2) Mokhatab, S.; Poe, W. A.; Mak, J. Y.; Mokhatab, S.; Poe, W. A.; Mak, J. Y. Natural Gas Fundamentals. Handbook of Natural Gas Transmission and Processing; Elsevier, 2015; pp 1-36.

(3) U.S. Energy Information Administration. Carbon Dioxide Emissions Coefficients. https://www.eia.gov/environment/ emissions/co2 vol mass.php (accessed Jun 15, 2017).

(4) Natural Resources and Geothermal Energy in the Netherlands; Ministry of Economic Affairs: The Hague, The Netherlands, 2015.

(5) Chabrelie, M. F.; Rojey, A. Prospects for Exploiting Stranded Gas Reserves; Gastech Conference, TX, 2000.

(6) Golombok, M.; Nikolic, D. Assessing Contaminated Gas. Explor. Prod. 2008, June, 73-75.

(7) Hammer, G.; Lübcke, T.; Kettner, R.; Pillarella, M. R.; Recknagel, H.; Commichau, A.; Neumann, H.-J.; Paczynska-Lahme, B. Natural Gas. In Ullmann's Encyclopedia of Industrial Chemistry; Wiley-VCH Verlag GmbH \& Co. KGaA: Weinheim, Germany, 2012; p 740.

(8) Woodcock, K. E.; Gottlieb, M. Gas, Natural. In Kirk-Othmer Encyclopedia of Chemical Technology; John Wiley and Sons, Inc., 2004; Vol. 12, pp 365-386.

(9) Nasr, G. G.; Connor, N. E. Fundamentals of Natural Gas. In Natural Gas Engineering and Safety Challenges; Springer International Publishing, 2014; pp 1-15.

(10) Kohl, A. L.; Nielsen, R. B. Alkanolamines for Hydrogen Sulfide and Carbon Dioxide Removal. In Gas Purification; Gulf Publishing Company, 1997; pp 40-186.

(11) Anbia, M.; Babaei, M. Novel Amine Modified Nanoporous SBA15 Sorbent for the Removal of $\mathrm{H}_{2} \mathrm{~S}$ from Gas Streams in the Presence of $\mathrm{CH}_{4}$. Int. J. Eng. 2014, 27 (11B), 1697-1704.

(12) Belmabkhout, Y.; De Weireld, G.; Sayari, A. Amine-Bearing Mesoporous Silica for $\mathrm{CO}_{2}$ and $\mathrm{H}_{2} \mathrm{~S}$ Removal from Natural Gas and Biogas. Langmuir 2009, 25 (23), 13275-13278.

(13) Belmabkhout, Y.; Heymans, N.; De Weireld, G.; Sayari, A. Simultaneous Adsorption of $\mathrm{H}_{2} \mathrm{~S}$ and $\mathrm{CO}_{2}$ on Triamine-Grafted PoreExpanded Mesoporous MCM-41 Silica. Energy Fuels 2011, 25 (3), 1310-1315.

(14) Chen, Q.; Fan, F.; Long, D.; Liu, X.; Liang, X.; Qiao, W.; Ling, L. Poly(ethyleneimine)-Loaded Silica Monolith with a Hierarchical Pore Structure for H2S Adsorptive Removal. Ind. Eng. Chem. Res. 2010, 49 (22), 11408-11414.

(15) Cong, T. N.; He, Y.; Chen, H.; Ding, Y.; Wen, D. Heat Transfer of Gas-Solid Two-Phase Mixtures Flowing through a Packed Bed under Constant Wall Heat Flux Conditions. Chem. Eng. J. 2007, 130 (1), $1-10$.

(16) Huang, Y. H.; Yang, R. T.; Chinn, D.; Munson, C. L. AmineGrafted MCM-48 and Silica Xerogel as Superior Sorbents for Acidic Gas Removal from Natural Gas. Ind. Eng. Chem. Res. 2003, 42 (12), 2427-2433.

(17) Jaiboon, V.; Yoosuk, B.; Prasassarakich, P. Amine Modified Silica Xerogel for H2S Removal at Low Temperature. Fuel Process. Technol. 2014, 128, 276-282.

(18) Yoosuk, B.; Wongsanga, T.; Prasassarakich, P. $\mathrm{CO}_{2}$ and $\mathrm{H}_{2} \mathrm{~S}$ Binary Sorption on Polyamine Modified Fumed Silica. Fuel 2016, 168, $47-53$. 
(19) Quan, W.; Wang, X.; Song, C. Selective Removal of $\mathrm{H}_{2} \mathrm{~S}$ from Bio-Gas Using Solid Amine-Based "Molecular Basket" Sorbent. Energy Fuels 2017, 31, 9517-9528.

(20) Alesi, W. R.; Kitchin, J. R. Evaluation of a Primary AmineFunctionalized Ion-Exchange Resin for $\mathrm{CO}_{2}$ Capture. Ind. Eng. Chem. Res. 2012, 51 (19), 6907-6915.

(21) Veneman, R.; Hilbers, T.; Brilman, D. W. F.; Kersten, S. R. A. $\mathrm{CO}_{2}$ Capture in a Continuous Gas-Solid Trickle Flow Reactor. Chem. Eng. J. 2016, 289, 191-202.

(22) Sutanto, S.; Dijkstra, J. W.; Pieterse, J. A. Z.; Boon, J.; Hauwert, P.; Brilman, D. W. F. $\mathrm{CO}_{2}$ Removal from Biogas with Supported Amine Sorbents: First Technical Evaluation Based on Experimental Data. Sep. Purif. Technol. 2017, 184, 12-25.

(23) Sonnleitner, E.; Schöny, G.; Hofbauer, H. Assessment of Zeolite 13X and Lewatit VP OC 1065 for Application in a Continuous Temperature Swing Adsorption Process for Biogas Upgrading. Biomass Convers. Biorefin. 2017, 1-17.

(24) Kunii, D.; Levenspiel, O. Fluidization Engineering, 2nd ed.; Butterworth-Heinemann, 1991.

(25) Krutka, H.; Sjostrom, S.; Starns, T.; Dillon, M.; Silverman, R. Post-Combustion $\mathrm{CO}_{2}$ Capture Using Solid Sorbents: 1 MWe Pilot Evaluation. Energy Procedia 2013, 37, 73-88.

(26) Nelson, T. O.; Kataria, A.; Mobley, P.; Soukri, M.; Tanthana, J. RTI's Solid Sorbent-Based $\mathrm{CO}_{2}$ Capture Process: Technical and Economic Lessons Learned for Application in Coal-Fired, NGCC, and Cement Plants. Energy Procedia 2017, 114, 2506-2524.

(27) Roy, S.; Mohanty, C. R.; Meikap, B. C. Multistage Fluidized Bed Reactor Performance Characterization for Adsorption of Carbon Dioxide. Ind. Eng. Chem. Res. 2009, 48 (23), 10718-10727.

(28) Das, D.; Samal, D. P.; Meikap, B. C. Removal of $\mathrm{CO}_{2}$ in a Multistage Fluidized Bed Reactor by Diethanol Amine Impregnated Activated Carbon. J. Environ. Sci. Health, Part A: Toxic/Hazard. Subst. Environ. Eng. 2016, 51 (9), 769-775.

(29) Schöny, G.; Zehetner, E.; Fuchs, J.; Pröll, T.; Sprachmann, G.; Hofbauer, H. Design of a Bench Scale Unit for Continuous CO2 Capture via Temperature Swing adsorption-Fluid-Dynamic Feasibility Study. Chem. Eng. Res. Des. 2016, 106, 155-167.

(30) Schöny, G.; Dietrich, F.; Fuchs, J.; Pröll, T.; Hofbauer, H. A Multi-Stage Fluidized Bed System for Continuous $\mathrm{CO}_{2}$ Capture by Means of Temperature Swing Adsorption - First Results from Bench Scale Experiments. Powder Technol. 2017, 316, 519-527.

(31) Dietrich, F.; Schöny, G.; Fuchs, J.; Hofbauer, H. Experimental Study of the Adsorber Performance in a Multi-Stage Fluidized Bed System for Continuous $\mathrm{CO}_{2}$ Capture by Means of Temperature Swing Adsorption. Fuel Process. Technol. 2018, 173, 103-111.

(32) Kohl, A. L.; Nielsen, R. B. Introduction. In Gas Purification; Gulf Publishing Company: Houston, TX, 1997; pp 1-39.

(33) Vanderschuren, J. The Plate Efficiency of Multistage FluidizedBed Adsorbers. Chem. Eng. J. 1981, 21, 1-9.

(34) Desai, R.; Hussain, M.; Ruthven, D. M. Adsorption of Water Vapor on Activated Alumina. I - Equilibrium Behaviour. Can. J. Chem. Eng. 1992, 70, 699-706.

(35) Blauwhoff, P. M. M.; van Swaaij, W. P. M. Simultaneous Mass Transfer of $\mathrm{H}_{2} \mathrm{~S}$ and $\mathrm{CO}_{2}$ with Complex Chemical Reactions in an Aqueous Di-Isopropanolamine Solution. Chem. Eng. Process. 1985, 19 (2), 67-83.

(36) Do, D. D. Practical Approaches of Pure Component Adsorption Equilibria. In Adsorption Analysis: Equilibria and Kinetics; Imperial College Press, 1998; pp 49-148.

(37) Lockett, M. J. Tray Efficiency. In Distillation Tray Fundamentals; Cambridge University Press, 1986; pp 118-127.

(38) Cholette, A.; Cloutier, L. Mixing Efficiency Determinations for Continuous Flow Systems. Can. J. Chem. Eng. 1959, 37 (3), 105-112.

(39) Ruthven, D. M. Dynamics of Adsorption Columns. In Principles of Adsorption and Adsorption Processes; John Wiley \& Sons, 1984; pp 220-273.

(40) LeVan, M. D.; Carta, G. Adsorption and Ion Exchange. In Perry's Chemical Engineers' Handbook; Green, D. W., Ed.; McGrawHill, 2008; pp 16-1-16-69.
(41) Yates, J. G. Effects of Temperature and Pressure on Gas-Solid Fluidization. Chem. Eng. Sci. 1996, 51 (2), 167-205. 